\title{
TCOM AMÉRICA LATINA \\ Orientações ideológicas nas informações científicas: o caso da abordagem do rompimento da barragem de Fundão presente na revista Veja
}

\section{Guilherme da Silva Lima e Mariana Moschem}

Resumo

Palavras-chave

DOI

Introdução
Este trabalho investigou as orientações ideológicas presentes em informações científicas. Dada à pluralidade de publicações desse tipo, delimitamos o caso para as produções que abordaram o rompimento da barragem de Fundão - um dos maiores crimes socioambientais do Brasil. Selecionamos a reportagem com base na revista de maior circulação nacional e delimitamos a reportagem especial da revista Veja sobre o assunto, que foi publicada em pouco menos de um mês após o rompimento, edição número 2454. Baseamo-nos nas contribuições do círculo de Bakhtin, especialmente no conceito de signo ideológico para fundamentar as análises apresentadas. Os principais resultados nos indicam a existência de orientações ideológicas que tendem a privilegiar determinadas interpretações do rompimento da barragem de Fundão em detrimento de outras.

Comunicação ambiental; Comunicação de risco; Jornalismo científico

https://doi.org/10.22323/3.01010204

Recebido em 16 de Abril de 2018

Aceito em 27 de Setembro de 2018

Publicado em 21 de Novembro de 2018

No dia 5 de novembro de 2015, a barragem de Fundão, em Minas Gerais, se rompeu causando um dos maiores crimes socioambientais no Brasil. A barragem de Fundão era gerida pela empresa Samarco Mineração S.A., uma joint venture criada, em 1977, pelas empresas mineradoras Vale S.A. e BHP Billiton. O evento destruiu o distrito de Bento Rodrigues no município de Mariana, além do rastro de destruição pela bacia do rio Doce. Por esses motivos, o rompimento foi alvo de inúmeras abordagens da mídia que tentou registrar os desdobramentos desse crime socioambiental.

A barragem de Fundão tinha capacidade de armazenar 55 milhões de metros cúbicos de rejeitos do processo de mineração. $\mathrm{O}$ rompimento causou grande 
impacto ambiental, com a destruição da fauna, flora e da bacia do rio Doce. Os impactos sociais não foram amenos. Além da morte de 19 pessoas, da destruição de imóveis e vilarejos, os rejeitos da Samarco impactaram as cidades que dependiam do rio Doce tanto para atividades econômicas quanto para atividades de infraestrutura e saneamento básico. Dentre os atingidos não podemos deixar de mencionar a comunidade dos índios Krenak, que vivem na bacia do Rio Doce entre as cidades mineiras de Resplendor e Conselheiro Pena e tinham o Uatu (rio doce) como entidade sagrada além de base de sustentabilidade da comunidade [Fiorott e Zaneti, 2017].

Frente aos diversos impactos socioambientais causados pelo rompimento da barragem de Fundão, corroboramos com a interpretação apresentada pelo grupo Poemas [2015], que entende o fato como uma catástrofe tecnológica, além de crime socioambiental. Tal consideração é justificada à medida que evidenciamos que as atividades minerárias são desenvolvidas por seres humanos que tomam como base fundamentos científicos e técnicos para extração e beneficiamento do minério.

Nesse sentido, a comunicação acerca do rompimento da barragem de Fundão pode apresentar elementos científicos e técnicos, seja devido aos processos relacionados à construção, manutenção e operação das atividades minerárias seja pelo desdobramento socioambiental do rompimento da barragem.

Tomando as reportagens sobre o rompimento da barragem de Fundão sob essa perspectiva, colocamos como problema de instigação a seguinte questão: quais são os direcionamentos ideológicos que são apresentados na revista de maior circulação nacional sobre o tema do rompimento da barragem de Fundão? Com o objetivo de responder essa pergunta analisamos o número 2454 da revista Veja com base nas contribuições do círculo de Bakhtin, que será mais detalhado em "Aprofundamento teórico", mais adiante neste artigo.

Entendemos ser fundamental investigar as orientações dadas ao jornalismo científico por periódicos de assuntos gerais com circulação nacional. Tais orientações são capazes de privilegiar determinadas perspectivas para a compreensão da realidade em prol de alguns grupos sociais. Ao dirigir as interpretações ao público, os periódicos podem trabalhar com o ofuscamento de determinados aspectos que seriam fundamentais para a compreensão da realidade e, a partir disso, tentar direcionar ou orientar a opinião pública.

Jornalismo científico e ideologia
As informações técnicas e científicas são abordadas por diversas atividades da comunicação social, dentre elas o jornalismo científico (JC), que tem como objetivo a comunicação de informações científicas, tecnológicas ou aquelas pertinentes à cultura científica.

Não podemos ofuscar a problemática existente frente à terminologia adotada para a comunicação de informações científicas e tecnológicas. Conhecemos os diversos termos utilizados por este campo de investigação, dentre os principais: divulgação científica (DC), popularização científica, comunicação da ciência, comunicação pública da ciência, alfabetização científica [Rocha, Massarani e Pedersoli, 2017]. Entendemos que os termos não são sinônimos, mas expressam perspectivas que concebem a atividade de comunicar elementos da cultura científica para a sociedade. 
Utilizamos a denominação JC para fazer referência a uma modalidade específica de DC que está baseada "na noticiabilidade, atualidade, periodicidade, universalidade e relevância social" [Rios et al., 2005, p. 116]. Estas não são as únicas características do JC, perspectivas contemporâneas destacam a importância do papel crítico do jornalista científico na produção desses suportes comunicativos [Rios et al., 2005; Caldas, 2010], contudo ainda é frequente na América Latina a abordagem de informações científicas e tecnológicas de maneira acrítica [Massarani e Buys, 2007].

No JC, jornalistas, repórteres, editores, cientistas, professores e outros cidadãos podem exercer a função de divulgador científico. Ressaltamos, porém, a possibilidade de hibridização de gêneros jornalísticos, de modo que interesses editoriais podem fundir gêneros visando o atendimento do público almejado e o escopo do veículo de comunicação. ${ }^{1}$

A partir de uma perspectiva linguística, existem duas vertentes consolidadas para se compreender o JC: a primeira estabelece que o JC é uma reformulação do discurso científico, ao passo que ele é produzido por uma espécie de tradução dos termos científicos para termos cotidianos ou familiares aos leitores, isto é, uma tradução de uma linguagem especializada para uma linguagem não especializada [Bueno, 1985; Bueno, 2009; Authier-Revuz, 1999; Epstein, 2012]; a segunda defende o JC como uma modalidade específica de gênero discursivo [Zamboni, 2001; Cunha, 2009; Cunha e Giordan, 2015].

Posicionamo-nos críticos à perspectiva da reformulação discursiva. Entendemos que essa posição está fundamentada em uma possível neutralidade no processo de reformulação discursiva, que para nós não existe. Ao ser produzido o JC nem sempre conta com um discurso fonte e quando o faz deturpa uma série de aspectos deste, tais como: alteração do destinatário do enunciado; alteração da estrutura da linguagem; alteração de aspectos semânticos e axiológicos do discurso, dentre outros [Lima, 2016]. Entendemos que considerar a reformulação discursiva como princípio da produção do JC pode ofuscar as orientações ideológicas existentes nessa modalidade de jornalismo especializado, uma vez que indica que determinada orientação é própria do discurso científico, consideração que por vezes pode estar equivocada.

Contudo, a perspectiva que sustenta o JC como uma modalidade de gênero discursivo também é insuficiente, visto que o JC pode ser produzido por diversos gêneros do discurso: notícia, reportagem, crônica, entrevista, editorial, carta, dentre outros.

Adotamos neste trabalho a perspectiva defendida por Grillo [2013], que concebe o JC como uma modalidade particular de relação dialógica estabelecida na inter-relação entre esferas de criação ideológicas, em especial a educação, o jornalismo e a ciência. Nesse sentido, o JC é produzido em meio a coerções de diferentes esferas de criação ideológica que disputam sentidos e tentam, por vezes, impor determinadas orientações aos suportes produzidos. A abordagem sensacionalista de alguns periódicos que se dedicam a DC exemplifica as coerções

\footnotetext{
${ }^{1}$ As referências ao jornalismo científico mencionadas neste trabalho devem incluir produções híbridas que visam a comunicação de aspectos científicos e técnicos seja do mundo natural ou das histórias, processos e desdobramentos das atividades científicas e técnicas.
} 
existentes, que nesse caso estão voltadas, sobretudo, para o lucro e a indústria cultural.

Em seu turno, as esferas de criação ideológica, “tem seu próprio modo de orientação para a realidade e refrata a realidade à sua própria maneira. Cada campo dispõe de sua própria função no conjunto da vida social" [Bakhtin, 2009, p. 33]. Com isso, a comunicação produzida pelo JC não é neutra, mas sim orientada de acordo com perspectivas socioideológicas dos grupos responsáveis pela sua produção.

Caldas [2010] problematiza as relações de poder existentes na produção da DC, destacando especialmente as tensões entre os jornalistas e cientistas. Em sua reflexão a autora destaca que:

Numa sociedade permeada por relações de poder, pelo discurso competente, em que se espera do jornalista científico que "estenda o tapete vermelho" para o cientista, reproduzindo de forma precisa, porém acrítica, o conteúdo das pesquisas, é necessário refletir sobre a atribuição desse papel à comunicação, no processo de popularização do conhecimento científico [Caldas, 2010, p. 32].

As relações de poder mencionadas são intensificadas pela própria natureza da DC, que em sua base carrega o termo "científico", que postula no senso comum um saber hierarquicamente superior a outros saberes produzidos pelo ser humano. ${ }^{2}$ Baseado nas contribuições de Adorno e Horkheimer sobre a indústria cultural e o esclarecimento, Lima e Giordan [2014] ressaltam que o termo "científico" da DC ou do JC faz referência à ciência, que

\begin{abstract}
baseada em formas de conduta que matematizam e numa estrutura conceitual precisa, a verdade esclarecida faz da racionalidade técnica a única via para compreensão do mundo e fundamenta-se no método, bem como nos princípios da objetividade e neutralidade. Sob essa perspectiva a ciência não é vista (...) como uma forma de representação simbólica produzida pelo Homem, mas a única capaz de alcançar a verdade esclarecida. [Lima e Giordan, 2014, p. 26]
\end{abstract}

Ainda que a comunidade científica questione os fundamentos mencionados, estes continuam sustentando o senso comum, podem ser encontrados em representações artísticas e na comunicação social. Em especial, na comunicação social há a ideia da representação precisa e acrítica do conhecimento científico, tal como apontado por Caldas [2010].

Almeida, Dal'Col e Massarani [2013] destacam as relações entre desdobramentos políticos e jurídicos referentes à ciência e tecnologia e a abordagem midiática, indicando relações de poder entre as esferas do Estado que exerceram coerções sobre a abordagem do JC:

\footnotetext{
${ }^{2}$ Ainda que a superioridade da ciência seja questionada por inúmeras pessoas, tal hierarquia é sustentada pela apropriação e incorporação de bens provenientes da cultura científica em detrimento de outros produtos ou práticas sociais, a saber: tecnologias de comunicação, transportes, medicina, produção energética, etc.
} 
A partir do momento em que a pesquisa com células-tronco embrionárias tornou-se o pivô de um julgamento no STF, o que intensificou as discussões sobre o assunto nas arenas política, jurídica e pública, o tema ganhou maior atenção da mídia, e o foco das reportagens se direcionou, sobretudo, para os aspectos políticos e jurídicos do assunto [Almeida, Dal'Col e Massarani, 2013, p. 1217].

O caso estudado pelas autoras ressalta a influência de setores do Estado na produção do JC, contudo estes não são os únicos setores a coagir a comunicação pública da ciência e da tecnologia. Santos e colaboradores [2013] ressaltaram coerções de setores privados na abordagem sobre saúde e ambiente no contexto da instalação da refinaria de petróleo em Suape-PE. De acordo com os autores:

\begin{abstract}
As vulnerabilidades e as situações de perigo presentes nos empreendimentos econômicos são ocultadas, enquanto promessas de benefícios econômicos e sociais deles advindos são tratados de forma privilegiada pela mídia. Dessa forma, há uma ideologia que sustenta a crença no desenvolvimento econômico e o menosprezo à precaução e preocupação com os impactos socioambientais, processo de alienação da população frente a seus interesses [Santos et al., 2013, pp. 3-4].
\end{abstract}

Os exemplos apresentados contribuem para questionarmos o papel do JC na sociedade contemporânea, especialmente quando diversos estudos apontam para condutas indesejáveis. Ao fazer uma ampla revisão das publicações sobre a comunicação pública da ciência na América Latina, Almeida, Amorim e Massarani [2017] destacam diversos elementos que nos fazem questionar qual o papel dessa atividade. Os autores ressaltam que é comum a abordagem: da produção científica sem abordar riscos e limitações das investigações e produtos científicos; idealizada da Ciência; com tratamento precário dos conceitos científico; da produção científica como grande acontecimento. Tais características nos indicam uma comunicação que não atende o princípio de democratização do saber. A análise realizada pelos autores indicou que
A avaliação geral é de que os meios de comunicação de massa não estão desempenhando adequadamente seu papel como um importante mediador entre ciência e sociedade, ainda longe de construir uma cultura científica sólida e inclusiva nos países latino-americanos e formar cidadãos críticos no que diz respeito a temas de ciência e tecnologia [Almeida, Amorim e Massarani, 2017, p. 67].

Entendemos que os diversos casos apresentados contribuem tanto com o afastamento do público quanto com a produção de interpretações equivocadas sobre Ciência e Tecnologia. Tais condições subsidiam o aprofundamento das desigualdades sociais, nesse caso com a concentração do conhecimento científico.

Pontes [2016] contribui com essa discussão e pontua que o jornalismo pode ser utilizado ideologicamente. Costa [2016], por sua vez, destaca as orientações ideológicas presentes na DC: a revista Ciência Hoje apresenta um antagonismo entre as perspectivas moderno-iluminista e pós-moderna, que defendem respectivamente: "uma visão de mundo sistêmica, totalizante e comprometida com 
a construção do futuro e (... ) práticas e valores de inspiração pós-moderna, definidos $(. .$.$) pela despolitização e pelo elogio do fragmentário e do contingente"$ [Costa, 2016, p. 48]. Além disso, o autor destaca que:

o discurso de divulgação científica constitui um campo relevante para a observação dos embates entre as forças que lutam pela hegemonia na construção dos sentidos e significados materializados nos enunciados concretos em circulação na sociedade [Costa, 2016, p. 48]

Medeiros [2012] corrobora com essa interpretação ao apontar que a maioria das representações, presentes na cobertura da clonagem e da pesquisa sobre células tronco destaca posturas cientificistas, isto é, que denota juízo de valor positivo às investigações sobre o tema. Resultado similar foi encontrado por Almeida, Dal'Col e Massarani [2013] ao investigar as reportagens sobre células tronco feitas pelo Jornal Nacional, que mostraram predominantemente valor positivo, ainda que tenham evidenciado a polêmica.

Pontes [2016] reflete sobre o jornalismo como possível ferramenta de dominação, que por meio da ideologia burguesa tenta deturpar a comunicação da realidade através de orientações determinadas pelas classes dominantes. No entanto, para Genro Filho, a ideologia não é exclusivamente uma ferramenta para a dominação da sociedade, mas sim um espaço de disputas, que contrapõe perspectivas opressoras e emancipatórias.
A ideologia é um sistema de ideias mais ou menos delineado que implica num compromisso do sujeito diante da totalidade do mundo histórico-social, e não apenas num compromisso epistemológico diante dos objetos reconhecidos em sua positividade. A ideologia implica numa postura ativa da consciência frente à realidade histórica do mundo, envolvendo negação ou afirmação desse mundo de parte do sujeito consciente. Negar a possibilidade da ideologia revolucionária é posicionar-se, ontologicamente, como objeto entre os objetos ou, na melhor das hipóteses, acreditar que a objetividade - por meio da teoria - pode desvelar sua "verdade" independente da postura efetivamente revolucionária do sujeito, a qual exige uma atividade prático-crítica. [Genro Filho, 1986, p. 97 apud Pontes, 2016, p. 155].

Nesse sentido, Genro Filho fala do jornalismo como conhecimento e ideologia, e não apenas como instrumento de dominação subordinado às classes dominantes. $\mathrm{O}$ jornalismo ressignifica os fatos sociais arraigados às disputas no âmbito das classes sociais. Assim como qualquer outra prática social, o JC possui orientações ideológicas e mesmo quando estas aparentam estar ausentes estão orientadas principalmente aos interesses das classes dominantes.

A ideologia não é um fenômeno genérico presente na consciência, ela se materializa nas ações humanas, nos seus produtos e nas formas de expressão [Medviédev, 2012]. No JC não é diferente, no entanto há a particularidade de que a ideologia relaciona-se especialmente com uma esfera da produção humana: a Ciência, que é objeto comunicativo do JC.

Ainda que a ciência e a ideologia tracem percursos diferentes, elas estabelecem relações mútuas. Enquanto a ciência busca explicar a realidade baseada em um 
modelo de racionalidade, a Ideologia tenta orientar a interpretação da realidade de acordo com interesses das classes sociais. As aproximações mais comuns entre elas são as orientações ideológicas para a produção científica, que impõem limitações aos escopos da investigação; bem como, a apropriação do conhecimento científico para os interesses das classes dominantes, que o usa em prol da manutenção da sociedade de classes.

Assim, pensar as relações entre a Ideologia e o JC não se restringe às produções da comunicação social, contempla também os projetos sociais fundamentados em interesses de classe. Com isso, torna-se fundamental discutir as relações entre a ideologia e o JC, uma vez que esta atividade é produzida em meio a interesses ideológicos que podem atender ao projeto de dominação das classes trabalhadoras ou ao projeto de emancipação humana.

Aprofundamento teórico
Pensar o JC e sua produção, delineando as orientações e valores presentes no discurso, requer um aprofundamento relacionado aos elementos linguísticos que sustentam a comunicação discursiva.

O círculo de Bakhtin propõe uma intepretação da produção linguística baseada no marxismo [Narzetti, 2013], de modo que a produção discursiva é determinada pela infraestrutura, isto é, as relações concretas de produção. A partir disso, a produção discursiva passa a ser compreendida como um produto de sujeitos socialmente organizados [Bakhtin, 2009]: "Razão pela qual as formas do signo [ideológico] são condicionadas tanto pela organização social de tais indivíduos como pelas condições em que a interação acontece" [Bakhtin, 2009, p. 45].

Todo signo é duplamente orientado para a realidade, se por um lado a compõe no momento concreto de produção discursiva no qual o enunciado está inserido, por outro refrata o real de acordo com as orientações das esferas de criação ideológicas que compunham e determinavam os contextos de produção do signo [Bakhtin, 2009]. Entender o signo ideológico como refração da realidade nos indica uma crítica à ideia de que a linguagem é capaz de representar fidedignamente o real. Tal característica fica mais clara quando Bakhtin [2009, p. 37] defende que
Cada domínio [esfera de criação ideológica] possui seu próprio material ideológico e formula signos e símbolos que lhe são específicos e que não são aplicáveis a outros domínios. O signo, então é criado por uma função ideológica precisa e permanece inseparável dela.

Tal afirmação pode ser justificada se tomarmos como referência o fato de que diferentes classes sociais produzem signos ideológicos distintos, pois estão orientadas de modos distintos para a realidade. Isto implica na delimitação do material ideológico. Ressaltamos, porém, que por vezes é possível notar classes de trabalhadores compartilhando signos ideológicos produzidos por classes dominantes, condição que pode ser explicada pela interpretação do conceito ideologia como produção de falsa consciência em prol da opressão dos trabalhadores. ${ }^{3}$

\footnotetext{
${ }^{3}$ Não nos adentraremos nesse debate com o intuito de manter a discussão apenas no escopo da proposta deste trabalho, para aprofundamento dessa interpretação indicamos Eagleton [1991].
} 
Devido a sua origem social, o signo ideológico poderá ser demarcado pelos diferentes interesses sociais característicos da luta de classes. Tal fato implica em disputas valorativas em torno do signo, condição que nos permite encontrar contradições presentes na sociedade que são refletidas ou refratadas pelos signos ideológicos.

De acordo com o círculo de Bakhtin, qualquer produto ideológico faz parte da realidade, assim como qualquer corpo físico, ferramenta de produção ou objeto de consumo. Com isso, a materialidade é uma característica fundamental para a produção do signo ideológico. Bakhtin [2009] usa o exemplo da foice e do martelo, que representam, antes de tudo, instrumentos de trabalho. Todavia, quando cruzados representam um símbolo do comunismo, isto é, fazem referência a um sentido externo às características desses instrumentos. Da mesma forma, um signo ideológico é produzido baseado na ampliação dos sentidos que os instrumentos que o compõem são capazes de apresentar, isto é, os signos ideológicos representam algo que está além dos limites impostos pela materialidade contida nos objetos.

Medviédev [2012, pp. 48-49], um dos principais membros do círculo de Bakhtin, contribui significativamente para o entendimento dos signos ideológicos e da própria ideologia, quando destaca que:

\begin{abstract}
As concepções de mundo, as crenças e mesmo os instáveis estados de espírito ideológicos também não existem no interior, nas cabeças, nas "almas" das pessoas. Eles tornam-se realidade ideológica somente quando realizados nas palavras, nas ações, na roupa, nas maneiras, nas organizações das pessoas e dos objetos, em uma palavra em algum material, eles tornam-se parte da realidade que circunda o homem.

O homem social está rodeado de fenômenos ideológicos, de "objetos-signo" dos mais diversos tipos e categorias: de palavras realizadas nas suas mais diversas formas, pronunciadas, escritas e outras; de afirmações científicas; de símbolos e crenças religiosas; de obras de arte, e assim por diante. Tudo isso em seu conjunto constitui o meio ideológico que envolve o homem por todos os lados em um círculo denso. Precisamente nesse meio vive e se desenvolve sua consciência [Medviédev, 2012, p. 57].
\end{abstract}

Os signos são determinados, portanto, pela interação social concreta que ocorre em meio às classes sociais e as relações de produção em que os sujeitos que os produzem integram, por isso podem apresentar indicadores de transformações sociais.

Quando em uso no âmbito da comunicação, o signo ideológico sempre promove apreciações dos sujeitos envolvidos. Bakhtin [2009] destaca que

\footnotetext{
Na realidade não são palavras o que pronunciamos ou escutamos, mas verdades ou mentiras, coisas boas ou más, importantes ou triviais, agradáveis ou desagradáveis, etc. A palavra está sempre carregada de um conteúdo ou de um sentido ideológico ou vivencial. É assim que compreendemos as palavras e somente reagimos àquelas que despertam em nós ressonâncias ideológicas ou concernentes à vida. [Bakhtin, 2009, pp. 98-99]
} 
Tais ressonâncias contemplam todas as formas da comunicação humana, dentre elas o JC, que é produzido em contextos específicos, por grupos sociais em meio a orientações ideológicas.

Os signos ideológicos são constituídos de diferentes vozes em distintas épocas e ecoam na sociedade [Costa, 2016]. Apesar disso, "A classe dominante tende a conferir ao signo ideológico um caráter intangível e acima das diferenças de classe, a fim de abafar ou de ocultar a luta dos índices sociais de valor que aí se trava, a fim de tornar o signo monovalente" [Bakhtin, 2009, p. 48].

Metodologia

Para atingir nossos objetivos, selecionamos a revista de maior circulação nacional com base nas informações da Associação Nacional de Editores de Revistas ANER: a revista Veja [ANER, s.d.]. Vale ressaltar que, de acordo com o sítio na rede mundial de computadores da PubliAbril, a revista Veja possui a circulação semanal de mais de 1 milhão de exemplares, alcançando um público de mais de 6 milhões de pessoas por semana, condição que coloca a revista como segunda revista com maior circulação no mundo.

Optamos por analisar a edição de número $2454,{ }^{4}$ publicada em 2 de dezembro de 2015, pois o periódico apresenta uma matéria especial sobre o rompimento da barragem de Fundão. A reportagem selecionada foi produzida quase um mês após o ocorrido, por isso eram disponíveis diversas informações para a imprensa e sociedade. A reportagem selecionada foi composta por comunicações de diversas origens sobre o rompimento: depoimentos de pessoas afetadas; estudos e ponderações de especialistas - um ecologista, um médico veterinário e uma bióloga; depoimentos da própria empresa; análises de outras instituições e pesquisadores; e a produção do próprio autor e editor que indica posicionamentos frente aos temas abordados.

Embora a revista não seja um periódico típico de JC, a reportagem analisada pode ser considerada uma produção híbrida que contempla diversos aspectos do JC: o rompimento da barragem de Fundão foi um desastre tecnológico, por isso todas as reportagens ligadas a este acontecimento estão relacionadas com a Ciência e a Tecnologia; no decorrer da reportagem são apresentadas informações de cunho científico e tecnológico sobre os rejeitos e também sobre a forma como estes afetaram e afetam o meio natural e social; a análise da fauna, flora e ictiofauna são baseadas em posicionamentos de representantes da cultura científica; a reportagem foi escrita com base em uma expedição que contou com três representantes da cultura científica, que foram essenciais para a composição do texto; a reportagem faz referência a diversas informações de origem técnica e científica apresentadas por instituições e pesquisadores.

Para as análises, nos pautamos nas contribuições do círculo de Bakhtin, que aborda, entre outros conceitos, os signos ideológicos. Tomamos como unidade de análise o enunciado com o intuito de analisar o signo ideológico a partir dos contextos sociodiscursivos nos quais eles foram produzidos.

\footnotetext{
${ }^{4}$ A edição selecionada pode ser acessada no acervo digital da revista que é disponibilizado em: https:/ /acervo.veja.abril.com.br/\#/edition/37696.
} 
Ressaltamos que não nos atemos a todos os signos ideológicos presentes na reportagem analisada. Por ser uma reportagem que foi composta por interpretações de cientistas, investigamos o papel do discurso desses sujeitos na produção da reportagem. Além disso, analisamos orações/frases que possuíam posicionamentos evidentes, sejam produzidos pelos autores da reportagem ou por entrevistados.

A análise do enunciado foi complementada pela análise semântica dos principais signos ideológicos presentes na reportagem - aqueles utilizados para representar o rompimento da barragem de Fundão. Para tanto, utilizamos o dicionário da língua portuguesa, pois apresenta os significados convencionais das palavras.

A reportagem escolhida apresenta uma diversidade de posições frente ao rompimento da barragem de Fundão. Acompanhados por representantes da comunidade científica, os repórteres percorreram o rastro de destruição provocado pela Samarco/Vale/BHP. Além da descrição da destruição causada pelos rejeitos de minério, a reportagem também apresentou opiniões de cientistas, controvérsias sobre as características dos rejeitos, o posicionamento de órgãos oficiais, sejam nacionais ou internacionais, bem como indicou alguns desafios da população atingida devido aos desdobramentos da destruição causada. Com essa diversidade de abordagens, a reportagem ocupa oito páginas da revista e apresenta, além do texto, fotos e infográficos. Devido à dimensão da reportagem apresentaremos nas análises a transcrição de fragmentos discursivos.

As demarcações ideológicas podem ser observadas, inclusive, no título e na linha fina da reportagem: "O mapa da destruição: acompanhada de um biólogo, a Veja fez uma viagem de mais de 700 quilômetros entre Mariana, em Minas Gerais, e Linhares, no Espírito Santo, para medir os reais danos ambientais em cada ponto atingido pelo amargo rio de lama que avança desde o rompimento da barragem de Fundão" [Zalis e Roris, 2015, p. 84]. Inicialmente é evidente o uso da autoridade científica (biólogo) para legitimar o trabalho apresentado pela reportagem. A palavra "reais" é um signo ideológico com marcante aspecto valorativo. Este signo sugere que outras análises continham equívocos ou deturpações sobre o que realmente aconteceu, ao contrário desta reportagem que representa de fato a verdade. O efeito de verdade é fortalecido pela legitimação da Ciência que é referenciada a partir da declaração de que a viagem foi acompanhada por um Biólogo.

O uso do discurso de autoridade para fortalecer a interpretação apresentada também pode ser encontrado em outros fragmentos da reportagem:

\footnotetext{
'É de surpreender que o príncipe da criação, o ser humano, seja capaz de transformar cenários de vida em cenários de morte e desolação', afirma Ruschi, com o rigor próprio dos cientistas momentaneamente estancado pela incontornável emoção provocada pelo impacto da visão de Bento Rodrigues, um povoado de 317 anos, onde se erguiam 200 casas, aniquiladas pela força do lamaçal. [Zalis e Roris, 2015, p. 86, grifo nosso]
}

No trecho novamente há a presença da autoridade científica, contudo vale ressaltar que as palavras com alto teor valorativo ficaram restritas à dramatização do 
rompimento da barragem de Fundão, de modo que não encontramos palavras capazes de produzir grandes impactos valorativos nas descrições ou análises feitas pela reportagem.

Além disso, a reportagem é composta por diversas considerações de representantes da comunidade científica, predominantemente com o intuito de apresentar uma perspectiva científica sobre a situação da flora, fauna e ictiofauna da região atingida pelos rejeitos de minério. Vale ressaltar, que as perspectivas apresentadas pelos profissionais que acompanharam a reportagem não são as únicas presentes no texto, que apresenta posicionamentos técnicos e científicos tanto de instituições, como a ONU, quanto de outros pesquisadores, como Milton Marcondes - diretor de pesquisa do projeto Baleia Jubarte. Assim, podemos considerar que o discurso de autoridade foi uma estratégia recorrente da reportagem para legitimar algumas das perspectivas apresentadas, característica que é comum do JC.

O uso do discurso de autoridade tecido a partir de considerações de representantes da comunidade científica também foi observado por Albuquerque e Oliveira [2005]. Ao investigarem a abordagem do transtorno do pânico em revistas nacionais, os autores destacaram que nas reportagens da revista Veja o "jornalista comanda o rumo das informações. O cientista (...) aparece como fonte e é mais usado como um discurso-autoridade do que como ator principal" [Albuquerque e Oliveira, 2005, p. 57]. Tal resultado nos indicia uma característica da abordagem de temas científicos da revista Veja.

Para além da participação de representantes da comunidade científica, a reportagem abordou a questão da responsabilidade pelo rompimento da barragem de Fundão. Tal responsabilidade é apresentada especialmente a partir das consequências e desdobramentos da destruição promovida pelos rejeitos e das ações e regulamentações do Estado frente às atividades minerárias. Consideramos que este aspecto em particular está articulado tanto à política técnica e científica quanto aos procedimentos técnicos para a operação das atividades minerárias.

A reportagem destaca que há mais de um responsável: "Muito provavelmente, houve negligência combinada com as precárias regulamentações brasileiras no setor de mineração" [Zalis e Roris, 2015, p. 92]. O trecho nos indica que o Estado provavelmente é um dos responsáveis pelo crime socioambiental, que está presente na crítica devido ao uso de "regulamentações brasileiras", contudo os demais sujeitos que deveriam contemplar a ideia de "negligência combinada" estão ocultos.

A reportagem ainda traz dados do Ministério de Minas e Energia que fortalecem essa interpretação, visto que destaca que das 735 barragens existentes no Estado de Minas Gerais, pouco mais de 30\% foram inspecionadas no ano anterior ao rompimento da barragem de Fundão. Tais informações somam-se com a crítica proferida por um especialista da área que alega: "As técnicas brasileiras são antiquadas". Tais críticas estão dirigidas, sobretudo, ao Estado e às "técnicas brasileiras" para a mineração e são de fato pertinentes para a compreensão das causas do rompimento da barragem de Fundão. 
Ressaltamos, porém, que o uso do termo "técnicas brasileiras" pode ser entendido aqui como um signo ideológico que está orientado para destacar facetas específicas da realidade orientadas para criticar o Estado. Entendemos que a produção enunciativa apresentada na reportagem busca construir o signo ideológico referente à crítica das técnicas utilizadas por meio do estabelecimento de um vínculo entre a técnica e o Estado, este último representado pelo termo genérico 'brasileiras'. Concomitantemente, o signo ideológico dissocia o vínculo entre a técnica utilizada e a escolha da mesma pelas empresas. Ressaltamos aqui uma orientação ideológica presente na reportagem em que o signo ideológico produzido não visa contemplar as diversas nuances da realidade, mas sim evidenciar determinadas críticas em detrimento de outras.

Apesar dessa referência às técnicas, a reportagem nos apresenta uma desvinculação entre a responsabilidade e a ciência e a técnica, situação que promove a interpretação de que o rompimento foi causado predominantemente pela negligência empresarial associado a decisões políticas. Não pretendemos negar tais considerações, contudo entendemos que as escolhas técnicas e científicas para a construção, manutenção e operação da barragem também contribuíram para o fato.

Ainda que seja questionável a afirmação de que a técnica possua orientação ideológica, o uso das técnicas não é interpretado pela comunidade científica como um ato neutro. Para o uso de determinados procedimentos científicos e técnicos são necessárias autorizações éticas. A abordagem jornalística da revista indica uma neutralidade ética no uso do conhecimento científico e técnico, uma vez que não questiona nenhum elemento que possa estar associado à ética técnica e científica. Essa abordagem é frequente na sociedade contemporânea e nos parece que se trata de uma estratégia para desvincular os procedimentos técnicos e científicos da produção industrial, esse afastamento favorece o uso da ética do mercado, que anseia, sobretudo, o lucro independentemente dos impactos e riscos socioambientais.

Outro ponto relevante que também envolve a ética científica e técnica é a relação desta catástrofe tecnológica com seus responsáveis, as empresas mineradoras. É evidente a escassez de críticas diretas à Samarco/Vale/BHP, ao passo que a responsabilidade da empresa pelo rompimento da barragem de Fundão não é explicita, exceto por duas passagens. A primeira expressa:

Na galeria de tragédias evitáveis que o Brasil mantém insistentemente aberta, o quadro mais novo é uma natureza morta. Ao desembocar no litoral do Espírito Santo em 21 de novembro, um sábado, o rio de lama e rejeitos químicos que vazou com o rompimento, no dia 5, da barragem de Fundão, de propriedade da mineradora Samarco, em Minas Gerais, concluiu a pintura de um cenário de rara devastação [Zalis e Roris, 2015, p. 86, grifo nosso]

Nesse trecho, a referência à empresa é explicita, no entanto, é apresentada por meio da voz passiva e associada ao uso de uma linguagem metafórica. Podemos destacar ainda os próprios vínculos utilizados para relacionar a barragem à empresa. No trecho, é expressa a ideia de que a barragem é de propriedade da mineradora, contudo a posse, por si só, é incapaz de determinar a reponsabilidade 
pelo crime. ${ }^{5}$ Salientamos, porém, que a barragem não era apenas propriedade da Samarco, mas também foi construída e era gerida pela mesma empresa.

O segundo trecho em que há vínculos diretos entre os nomes das empresas envolvidas e a reponsabilidade pelo rompimento da barragem de Fundão apresenta o seguinte:

\begin{abstract}
Depois do acidente, ficou claro que a Samarco, uma joint venture da brasileira Vale com a anglo-australiana BHP Billiton, estava informada dos riscos de ruptura da barragem de Fundão. (...) Em 2013, a Samarco foi avisada de problemas pelo instituto Prístino, uma organização sem fins lucrativos que realizou o estudo no local a mando do Ministério Público Estadual. Alguns anos antes, em 2009, a empresa Rescue Training International (RTI) já tinha sido contratada pela própria Samarco para prestar consultoria na área de emergência. Na ocasião, foi sugerido realizar as medições com apoio de telemetria. (...) O plano ficou engavetado porque era caro [Zalis e Roris, 2015, p. 90].
\end{abstract}

Como pode ser visto, a reportagem atribui às empresas a ciência dos riscos de ruptura da barragem. A responsabilidade está fortemente fundamentada na negligência, pois as informações presentes destacam os avisos recebidos pela empresa alegando os riscos de rompimento da barragem. Vale ressaltar, que diferentemente de outros trechos como aqueles em que a revista critica o Estado, não há posicionamento analítico no enunciado, os vínculos entre as empresas e o rompimento da barragem de Fundão são produzidos por meio de enunciados descritivos.

Outras produções enunciativas corroboram com o ofuscamento dos responsáveis diretos por esse crime socioambiental, como podemos ver nos seguintes fragmentos: "o rio de lama e rejeitos químicos que vazou"; "um dos pioneiros do ambientalismo no Brasil, em seus estudos pela bacia do Rio Doce, dramaticamente atingida pelo acidente" [Zalis e Roris, 2015, p. 86]; destacamos que em ambos os fragmentos não existem referências aos atos que proporcionaram o crime socioambiental, quão menos os nomes das empresas responsáveis. No primeiro trecho, "rejeitos químicos" é o sujeito do predicativo vazou; assim como a bacia foi atingida por um acidente, em que os responsáveis estão ocultos. Assim entendemos que a questão da ética científica e técnica é abordada por uma suposta neutralidade pela reportagem, condição que produz um afastamento entre o responsável e o fato ocorrido. Esse tipo de produção enunciativa ofusca determinados sujeitos diretamente relacionados com os desdobramentos e causas concretas do rompimento da barragem de Fundão, bem como estabelece uma orientação específica para a intepretação do caso, que para a revista deve ser tratado como acidente.

Em todo este trabalho é possível notar que ao fazermos referência ao rompimento da barragem utilizamos, predominantemente, a terminologia crime, em consonância com a legislação brasileira, pois foram diversos os crimes cometidos

\footnotetext{
${ }^{5}$ A título de exemplo, é possível pensar em inúmeras situações desse tipo, uma delas: o carro era de João, mas o responsável pelo acidente foi Pedro que estava dirigindo; aqui o sujeito que tem a posse do objeto não é o responsável pelo ocorrido. Por isso, entendemos que a declaração de posse não é suficiente para demarcar o responsável.
} 
pela Samarco/Vale/BHP devido ao rompimento da barragem, a saber: homicídios, inundação, desabamento, lesão corporal, além de crimes ambientais. De acordo com a denúncia do Ministério Público Federal, a Samarco responde por 15 crimes. $^{6}$

Na reportagem são apresentados os desdobramentos causados pelos rejeitos de minério, tais como: os danos à natureza, as mortes de pessoas, a destruição de propriedades particulares e os danos ao abastecimento de água; porém, as referências são feitas baseadas na destruição pela lama ou por meio da voz passiva.

Os termos "acidente", "desastre" e "tragédia" também são usados como signos ideológicos na reportagem, vale ressaltar que acordo com o dicionário da língua portuguesa os termos usados pela reportagem denotam:

“Acidente: 1. Acontecimento casual, fortuito, imprevisto. 2. Acontecimento infeliz, casual ou não, e de que resulta ferimento, dano, estrago, prejuízo, avaria, ruína, etc. desastre" [Ferreira, 2004, p. 32]

"Desastre: acontecimento calamitoso, especialmente o que ocorre de súbito e ocasionando grande dano ou prejuízo. 2. Acidente. 3. Mau êxito; fracasso." [Ferreira, 2004, p. 630]

“Tragédia: (...) 4. Acontecimento que desperta lástima ou horror; ocorrência funesta; sinistro. 5. Mau fardo; desgraço; infortuito" [Ferreira, 2004, p. 1972]

Não temos aqui o intuito de dicionarizar os signos ideológicos, mas sim de apresentar o significado comum da palavra, que se tornará signo ideológico na reportagem devido sua relação com o contexto de uso. Assim, tendo como referência a multiplicidade de termos que poderiam ser utilizados, cujos significados possuem posições valorativas diferentes, a própria escolha do termo indicia o horizonte ideológico no qual a reportagem pode ser enquadrada. Tal fato é acentuado devido à ausência de outras terminologias.

Com o propósito de fazer uma análise comparativa dos significados que determinadas palavras expressam apresentamos aquela que utilizamos nesse artigo para fazer referência ao rompimento da barragem de Fundão:

Crime: 1. [direito] Segundo o conceito formal, violação culpável da lei penal; delito. 2. [direito] segundo o conceito substancial, ofensa de um bem jurídico tutelado pela lei penal. 3. [direito] segundo o conceito analítico, fato típico, antijurídico culpável. 4. Qualquer ato que suscita a reação organizada da sociedade. 5. Ato digno de repreensão ou castigo. 6. Ato condenável, de consequências funestas ou desagradáveis [Ferreira, 2004, p. 574].

Uma análise comparativa nos mostra que os termos utilizados pela reportagem denotam acontecimentos, cujos responsáveis não estão na centralidade dos

\footnotetext{
${ }^{6}$ Ressaltamos que a justiça brasileira ainda não concluiu o processo. Contudo, as evidências de diversos crimes são diversas e documentadas inclusive pela mídia. A responsabilidade pelo crime é reconhecida pela Samarco, Vale e BHP, que se comprometeram com diversas ações de reparação. Para saber mais recomendamos os documentos do Ministério Público Federal: "denúncia compilada final" disponível em: http://www.mpf.mp.br/mg/sala-de-imprensa/docs/denuncia-samarco/view; Termo de ajustamento preliminar entre Ministério Público Federal, Samarco Mineração S/A, Vale S/A e BHP Billiton Brasil LTDA, disponível em: http:/ /www.mpf.mp.br/mg/sala-deimprensa/docs/termo-de-acordo-preliminar-caso-samarco/view; Ação Civil Pública Samarco, disponível em: http:/ / www.mpf.mp.br/mg/sala-de-imprensa/docs/acp-samarco/view.
} 
mesmos. Ao contrário de crime, que denota ato, isto é, uma ação cometida por alguém ou algo. Não fazemos a comparação para defender o termo que a reportagem deveria usar, mas para mostrar que os signos ideológicos expressam orientações para interpretar a realidade. Os signos utilizados pela reportagem para fazer referência ao rompimento da barragem (acidente, desastre, tragédia) não carecem de sujeitos responsáveis pelas ações e, por isso, exime o enunciador (repórter) de fazer referências aos atos que proporcionaram o crime socioambiental. Assim, ao utilizar os signos acidente, desastres e tragédias a reportagem assume uma posição ideológica propícia para ocultar os responsáveis pelo rompimento da barragem de Fundão. Ao mesmo tempo, esta abordagem distancia problemas sociocientíficos inerentes a esse crime socioambiental, fazendo com que os aspectos técnicos e científicos sejam subordinados ao acontecimento acidental, produto especialmente de uma conjuntura política (leis inadequadas). Esta subordinação sustenta a ausência da discussão ética mencionada anteriormente, uma vez que a abordagem evidencia o fato como acontecimento desvinculado de seu responsável.

Considerações finais
O trabalho que apresentamos aborda especialmente as orientações ideológicas presentes nas reportagens com informações científicas, no caso uma composição híbrida de JC, para isso fundamentamos as análises no conceito de signo ideológico proposto pelo círculo de Bakhtin de modo a tecer reflexões que possam contribuir para a compreensão do JC em aspectos teóricos e metodológicos.

As orientações ideológicas apresentadas nas análises mostraram especialmente o destaque de determinados aspectos do real em detrimento de outros. Esta orientação foi produzida por uma série de artifícios, dentre eles: o uso do discurso de autoridade expresso por cientistas para legitimar as interpretações presentes na revista; a abordagem de uma ética científica e técnica supostamente neutra que promove a desvinculação entre os responsáveis e os acontecimentos; e uso de signos ideológicos que representam o rompimento como acontecimento e não como ato, fato que pode induzir uma interpretação baseada na ausência de responsáveis.

Encontramos uma orientação ideológica clara que tende a atenuar a produção de valores negativos à Samarco/Vale/BHP associada à crítica incisiva e direta ao Estado. Tal orientação representa, para nós, o compromisso da revista com determinados setores da sociedade que buscam a manutenção do modelo econômico e do imaginário popular em que a crítica ao Estado é hipertrofiada em correlação inversa à crítica aos setores empresarias, característica típica do neoliberalismo. Tais resultados, são fortalecidos pelas considerações de C. L. Silva [2016] que destaca o compromisso da revista Veja com leitores que apoiam o neoliberalismo, Valle [2012, p. 140] que ressalta que "A pretensa neutralidade de Veja é, ao contrário, um forte arrimo ao neoliberalismo", bem como pelas considerações de Brandão e M. H. d. Silva [2017, p. 41]: “Veja foi um dos principais veículos da imprensa responsáveis pelo fomento das ideias liberais no país, incentivando sua nova onda, o neoliberalismo, que se estabeleceu no Brasil na década de 1990".

Salientar as orientações ideológicas presentes na Veja não é novidade, porém a presença dessas orientações em reportagens que abordam contextos sociocientíficos não havia sido investigada com destaque. Reconhecemos que essas orientações podem ser fruto também da formação do jornalista, contudo a comparação com 
outros resultados de pesquisa nos indica que as orientações ideológicas presentes na reportagem analisada compõem a base editorial da revista.

Por fim, ressaltamos que a investigação apresentada neste artigo contribui para a pesquisa sobre as características que podem ser encontradas no JC e em produções híbridas e potencialmente para as investigações acerca das orientações ideológicas presentes nesses gêneros comunicativos. Acreditamos que a comunidade científica precisa aprofundar tais discussões para melhor compreender a comunicação realizada pela mídia e para exercer coerções sobre a mídia a fim de contribuir com a qualidade da comunicação social que é produzida sobre temas sociocientíficos.

\section{Referências}

ALBUQUERQUE, E. C. R. T. e OLIVEIRA, A. D. (2005). ‘O pânico na mídia - a abordagem das revistas Veja, Isto É, Galileu e Superinteressante sobre a síndrome do pânico'. Comunicação e Informação 8 (1), pp. 53-59. (Acesso em ).

ALMEIDA, C., AMORIM, L. e MASSARANI, L. (2017). 'Ciencia y medios masivos de comunicación en América Latina'. Em: Aproximaciones a la investigación en divulgación de la ciencia en América Latina a partir de sus artículos académicos. Ed. por MASSARANI, L. e ROCHA, M. Rio de Janeiro, Brasil: COC.

ALMEIDA, C., DAL'COL, F. L. e MASSARANI, L. (2013). 'Controvérsia científica no telejornalismo brasileiro: um estudo sobre a cobertura das células-tronco no Jornal Nacional'. História, Ciências, Saúde-Manguinhos 20 (suppl 1), pp. 1203-1223. https://doi.org/10.1590/s0104-59702013000400007.

ANER - ASSOCIAÇÃO NACIONAL DE EDITORES DE REVISTAS (s.d.). Revistas Semanais - $2013 \times 2014$ (Jan a Set).

URL: http://aner.org.br/dados-de-mercado/circulacao/.

AUTHIER-REVUZ, J. (1999). 'Dialogismo e divulgação científica'. Rua: revista do núcleo de desenvolvimento da criatividade 5 (1). URL: https://periodicos . sbu . un icamp.br/ojs/index.php/rua/article/view/8640645.

BAKHTIN, M. (VOLOCHÍNOV, V. N.) (2009). Marxismo e filosofia da linguagem: problemas fundamentais do método sociológico na ciência da linguagem. São Paulo, Brasil: Hucitec editora.

BRANDÃO, L. e SILVA, M. H. da (2017). 'A emergência do neoliberalismo no Brasil: um estudo sobre a revista Veja no contexto das eleições presidenciais de 1989'. Estudos em Comunicação (24), pp. 27-42. https://doi.org/10.20287/ec.n24.a02.

BUENO, W. (1985). 'Jornalismo Cientifico no Brasil: Os Compromissos de uma prática dependente'. Doutorado em Ciências da Comunicação. Supervisor: José Marques de Melo. São Paulo, Brasil: Escola de Comunicação e Arte, Universidade de São Paulo, USP.

- (2009). 'Jornalismo científico: revisitando o conceito'. Em: Jornalismo científico e desenvolvimento sustentável. Ed. por VICTOR, C., CALDAS, G. e BORTOLIERO, S. São Paulo, Brasil.

CALDAS, G. (2010). 'Divulgaçao científica e relações de poder.' Informação \& Informação 15 (1esp), p. 31. https://doi.org/10.5433/1981-8920.2010v15n1espp31.

COSTA, L. R. (2016). 'Ideologia e divulgação científica: uma análise bakhtiniana do discurso da revista Ciência Hoje'. Bakhtiniana: Revista de Estudos do Discurso 11 (2), pp. 33-51. https://doi.org/10.1590/2176-457323536. 
CUNHA, M. B. (2009). 'A percepção de Ciência e Tecnologia dos estudantes do ensino médio e a divulgação científica'. Doutorado. São Paulo, Brasil: Faculdade de Educação, Universidade de São Paulo.

CUNHA, M. B. e GIORDAN, M. (2015). 'Divulgação científica na sala de aula: implicações de um gênero'. Em: Divulgação científica na sala de aula: perspectivas e possibilidades. Ijuí, Brasil: Editora Unijuí.

EAGLETON, T. (1991). Ideology: an introduction. London, U.K.: Verso.

EPSTEIN, I. (2012). 'Comunicação da Ciência: rumo a uma teoria da divulgação científica'. Espaço aberto.

URL: http://www.revistas.usp.br/organicom/article/view/139126.

FERREIRA, A. B. H. (2004). Novo dicionário Aurélio da língua portuguesa. $3^{\mathrm{a}}$ ed. Curitiba, Brasil: Positivo.

FIOROTT, T. H. e ZANETI, I. C. B. B. (2017). ‘Tragédia do Povo Krenak pela Morte do Rio Doce / Uatu, no Desastre da Samarco / Vale/ BHP, Brasil'. Fronteiras: Journal of Social, Technological and Environmental Science 6 (2), p. 127. https://doi.org/10.21664/2238-8869.2017v6i2.p127-146.

GRILLO, S. V. C. (2013). 'Divulgação científica: linguagens, esferas e gêneros'. Livre-docência em Filologia e Língua Portuguesa. São Paulo, Brasil: Faculdade de Filosofia, Letras e Ciências Humanas, Universidade de São Paulo.

LIMA, G. S. (2016). ‘O professor e a divulgação científica: apropriação e uso em situações formais de ensino'. Doutorado. São Paulo, Brasil: Faculdade de Educação, Universidade de São Paulo. URL: http://www.teses.usp. br/teses /disponiveis/48/48134/tde-16082016-093959/pt-br.php.

LIMA, G. S. e GIORDAN, M. (2014). 'Entre o Esclarecimento e a Indústria Cultural: reflexões sobre a divulgação do conhecimento científico'. Em: Mídias e Divulgação Científica. Ed. por TAVARES, D. e REZENDE, R. Rio de Janeiro, Brasil: Ciências e Cognição, pp. 12-32.

MASSARANI, L. e BUYS, B. (2007). 'Science in the Press in Nine Latin American Countries'. Brazilian Journalism Research 3 (2), pp. 77-96. https://doi.org/10.25200/bjr.v3n2.2007.120.

MEDEIROS, F. N. d. S. (2012). 'As múltiplas representações de Dolly nos discursos sobre a clonagem e as pesquisas com células-tronco na imprensa brasileira'. Intercom: Revista Brasileira de Ciências da Comunicação 35 (1), pp. 93-110. https://doi.org/10.1590/s1809-58442012000100006.

MEDVIÉDEV, P. N. (2012). O método formal nos estudos literários: introdução crítica a uma poética sociológica. São Paulo, Brasil: Contexto.

NARZETTI, C. (2013). 'A filosofia da linguagem de V. Voloshinov e o conceito de ideologia'. Alfa 57 (2), pp. 367-388. https://doi.org/10.1590/s1981-57942013000200002.

POEMAS (2015). Antes fosse mais leve a carga: avaliação dos aspectos econômicos, políticos e sociais do desastre da Samarco/Vale/BHP em Mariana (MG). Mimeo.

PONTES, F. S. (2016). 'O conceito de ideologia na teoria do jornalismo de Adelmo Genro Filho'. Galáxia (São Paulo) (32), pp. 151-162. https://doi.org/10.1590/1982-25542016223601.

RIOS, A. O., MACHADO, A. C., KNOLL, F. C., OLIVEIRA, M. e SILVA, T. C. F. (2005). 'Jornalismo científico: o compromisso de divulgar ciência à sociedade'. Publicatio UEPG: Ciências Humanas, Linguistica, Letras e Artes 13 (2), pp. 113-119. 
ROCHA, M., MASSARANI, L. e PEDERSOLI, C. (2017). ‘La divulgación de la ciencia en América Latina: términos, definiciones y campo académico'. Em: Aproximaciones a la investigación en divulgación de la ciencia en América Latina a partir de sus artículos académicos. Ed. por MASSARANI, L., ROCHA, M., PEDERSOLI, C., ALMEIDA, C., AMORIM, L., CAMBRE, M., NEPOTE, A. C., NOBERTO ROCHA, J., AGUIRRE, C., GONÇALVEZ, J. C., CORDIOLI, L. e FERREIRA, F. $1^{\text {a }}$ ed. Rio de Janeiro, Brazil: RedPOP e Casa de Oswaldo Cruz, pp. 39-58.

SANTOS, M. O. S. D., GURGEL, A. D. M., OLIVEIRA, G. H. D., GOMES, I. M. D. A. M., GURGEL, I. G. D. e SILVA AUGUSTO, L. G. da (2013). 'Análise crítica do discurso da mídia impressa sobre a saúde e o ambiente no contexto da instalação da refinaria de petróleo em Suape, PE'. Revista Eletrônica de Comunicação, Informação e Inovação em Saúde (RECIIS) 6 (4). https://doi.org/10.3395/reciis.v6i4.sup1.724pt.

SILVA, C. L. (2016). 'A direita e sua imprensa: o papel da revista Veja'. Em: A onda conservadora: ensaios sobre os atuais tempos sombrios no Brasil. Ed. por DEMIER, F. e HOEVLER, R. Rio de Janeiro, Brasil: Mauad, pp. 125-135.

VALLE, M. R. do (2012). '1968-2008: O Veja "Way of Life"'. Intercom: RBCC 35 (2), pp. 129-147. https://doi .org/10.1590/s1809-58442012000200007.

ZALIS, P. e RORIS, J. (2015). ‘O mapa da destruição. Acompanhada de um biólogo, a Veja fez uma viagem de mais de 700 quilômetros entre mariana, em Minas Gerais, e Linhares, no Espirito Santo, para medir os reais danos ambientas em cada ponto atingido pelo amargo rio de lama que avança desde o rompimento da barragem de Fundão'. Veja 2454, pp. 84-92.

ZAMBONI, L. M. S. (2001). Cientista, jornalista e a divulgação científica: subjetividade e heterogeneidade no discurso de divulgação científica. Campinas, Brasil: Autores associados.

\section{Autores}

Guilherme da Silva Lima é professor do departamento de Física da Universidade Federal de Ouro Preto. Interesses de pesquisa: divulgação científica, interações entre a cultura científica as artes e a educação científica. E-mail: glima@ufop.edu.br.

Mariana Moschem é estudante de jornalismo da Universidade Federal de Ouro Preto, inspirada nas diversas áreas contempladas pela escrita e pelo audiovisual, e também pelos aspectos relacionados ao meio-ambiente. Encontro nessa profissão, e também na pesquisa, um refúgio no qual posso inovar, e trazer novas histórias e/ou considerações diferentes daquilo que já foi contado.

E-mail: marianamoschem@gmail.com.

\section{Como citar}

Lima, G. S. e Moschem, M. (2018). ‘Orientações ideológicas nas informações científicas: o caso da abordagem do rompimento da barragem de Fundão presente na revista Veja'. JCOM - América Latina 01 (01), A04.

https://doi.org/10.22323/3.01010204.

(c) $\mathrm{O}(\mathrm{s})$ autor(es). Esta publicação é disponibilizada nos termos da licença Atribuição - Não Comercial — SemDerivações 4.0 da Creative Commons. ISSN n.d. Publicado pela SISSA Medialab. jcomal.sissa.it 